\title{
GCU
}

Glasgow Caledonian

University

University for the Common Good

\section{Psychometric properties of the pelvic organ prolapse symptom score}

Hagen, Suzanne; Glazener, Cathryn M.A.; Sinclair, L.; Stark, D.; Bugge, C.

Published in:

BJOG: An International Journal of Obstetrics and Gynaecology

DOI:

10.1111/j.1471-0528.2008.01903.x

Publication date:

2009

Document Version

Author accepted manuscript

Link to publication in ResearchOnline

Citation for published version (Harvard):

Hagen, S, Glazener, CMA, Sinclair, L, Stark, D \& Bugge, C 2009, 'Psychometric properties of the pelvic organ prolapse symptom score', BJOG: An International Journal of Obstetrics and Gynaecology, vol. 116, no. 1, pp. 25-31. https://doi.org/10.1111/j.1471-0528.2008.01903.x

\section{General rights}

Copyright and moral rights for the publications made accessible in the public portal are retained by the authors and/or other copyright owners and it is a condition of accessing publications that users recognise and abide by the legal requirements associated with these rights.

Take down policy

If you believe that this document breaches copyright please view our takedown policy at https://edshare.gcu.ac.uk/id/eprint/5179 for details of how to contact us. 
1 TITLE PAGE

2

3 TITLE Psychometric properties of the Pelvic Organ Prolapse Symptom Score

4 (POP-SS)

5

6 RUNNING TITLE The pelvic organ prolapse symptom score (POP-SS)

7

8 AUTHORS

9 Dr Hagen, Suzanne (corresponding author)

10 Urogenital Disorders Programme Leader

11 Nursing, Midwifery and Allied Health Professions Research Unit

12 Glasgow Caledonian University

13 Cowcaddens Road

14 Glasgow G4 OBA

15 Telephone: 01413318104 E-mail: s.hagen@gcal.ac.uk

16

17 Dr Glazener, Cathryn

18 Gynaecologist \& Reader in Health Services Research

19 Health Services Research Unit, Health Sciences Building

20 Foresterhill

21 Aberdeen AB25 2ZD

22

23 Ms Sinclair, Lesley (details given are for post held at time of writing)

24 Urogenital Disorders Research Fellow

25 Nursing, Midwifery and Allied Health Professions Research Unit

26 Glasgow Caledonian University

27 Cowcaddens Road

28 Glasgow G4 0BA 
30 Mrs Stark, Diane

31 Superintendent Physiotherapist

32 Southern General Hospital

331345 Govan Road

34 Glasgow G51 4TF

35

36 Dr Bugge, Carol

37 Senior Lecturer

38 Department of Nursing and Midwifery

39 University of Stirling

40 Stirling FK9 4LA

41

42 
Objective; to assess the internal consistency, construct validity and sensitivity to change of a pelvic organ prolapse symptom score (POP-SS).

Design; analysis of data from three prolapse studies, including symptomatic and asymptomatic women, who completed the POP-SS.

Setting; 1) a community setting in New Zealand; 2) two gynaecology outpatient departments in Scotland; 3) a gynaecological surgery department in Scotland.

Population or sample; 1) participants from a survey of post-natal women at 12 year

51 follow up, invited to complete a prolapse questionnaire and have prolapse assessment; 2) new gynaecology outpatients presenting with prolapse symptoms, randomised to pelvic floor muscle training (PFMT) or control; 3) women having anterior and/or posterior prolapse surgery, randomised to mesh insert or no mesh.

Methods; data were analysed to assess internal consistency, construct validity and sensitivity to change of the POP-SS.

Main outcome measures; Cronbach's alpha, significance of differences in POP-SS scores between studies, significance of difference in POP-SS scores pre- to postintervention.

Results; For internal consistency, Cronbach's alpha ranged from 0.723 to 0.828 . Women having surgery had higher POP-SS scores than those having conservative management (mean difference 5.0, 95\% confidence interval 3.1 to 6.9 ), who in turn

63 had higher scores than the asymptomatic women (mean difference $5.9,95 \% \mathrm{Cl} 4.4$ 64 to 7.4). Significant differences in POP-SS score were detected after surgery and PFMT. The improvement due to surgery was significantly greater than that associated with PFMT $(z=-3.006, p=0.003)$.

Conclusions; The POP-SS has good internal consistency and construct validity, and is sensitive to change. ( 250 words) 
70 Keywords; pelvic organ prolapse, outcome measure, psychometric properties,

71 internal consistency, construct validity, sensitivity to change

72

73

74 
INTRODUCTION

76 Pelvic organ prolapse (POP), a common female condition, is symptomatic descent,

77 from the normal anatomical position, of the vaginal walls, apex or vault ${ }^{1}$. Women 78 with prolapse present with a variety of symptoms (vaginal, urinary, bowel, back, 79 abdominal and sexual symptoms). Some of these symptoms are specifically 80 associated with the descending pelvic organs protruding into the vaginal canal, for 81 example, feeling of a bulge or something coming down. Others, such as urinary and 82 bowel problems, can co-exist and may be related to or independent of the prolapse. 83 It is important in research and clinical practice that we quantify such symptoms using 84 standardised instruments with known psychometric properties.

Many instruments exist for measuring urinary symptoms and associated quality of life, including 17 questionnaires which the International Consultation on Incontinence (ICI) classed as Grade A (i.e. having established reliability, validity and responsiveness demonstrated in one or more datasets) ${ }^{1}$. Far fewer are available for the specific symptoms of prolapse. The $\mathrm{ICI}$ in $2005{ }^{1}$ concluded that questionnaires in this area were "poorly developed to date and required encouragement"; two questionnaires of Grade B (validity and reliability established with rigour, or validity, 93 reliability and responsiveness indicated) were identified (Pelvic Floor Disorder 94 Inventory (PFDI) ${ }^{2}$ and Pelvic Floor Impact Questionnaire (PFIQ) ${ }^{2}$ ), and an additional 95 five which were in early development (Grade C) (e.g. P-QoL, ICIQ Vaginal Symptoms 96 Questionnaire). Since then work has been published on the above prolapse measures (short-form 99 versions of the PFDI and PFIQ ${ }^{3}$; the P-QoL ${ }^{4}$; ICIQ Vaginal Symptoms Questionnaire

$100{ }^{5}$ ). The most prominent of these measures ${ }^{2,4}$ are fairly lengthy, cover a range of 101 symptoms and include a number of subscales, for example relating to urinary and 102 bowel symptoms. It could be argued that these commonly co-existing symptoms are 
103 better measured using validated, condition-specific instruments such as those

104 developed by the International Consultation on Incontinence Questionnaire (ICIQ)

105 group $^{6}$, and that there remains a need for a brief symptom index which encapsulates

106 the presence and extent of key prolapse symptoms. We report here on a scale

107 which fulfils this need.

108

109 At the start of a programme of work on prolapse in 2000 , when we sought a brief

110 validated prolapse symptom scale, no suitable scale was available. We thus

111 developed a simple set of key questions covering the symptoms caused or

112 exacerbated specifically by prolapse which could serve as the primary outcome

113 measure for subsequent randomised controlled trials of various interventions for

114 POP. The key questions formed the basis for a POP symptom scale (POP-SS).

115

116 Our intention was to supplement the POP-SS with a number of existing validated

117 scales aimed specifically at urinary (ICIQ-UI SF ${ }^{7}$ ), bowel (ICIQ-BS ${ }^{6}$ ) and sexual

118 symptoms (PISQ-12 ${ }^{8}$ ), so that these functions could be assessed independently.

120 We administered the POP-SS to women in a number of research studies in order to

121 generate data on its acceptability and performance. This article presents the findings

122 regarding psychometric properties of the POP-SS, including internal consistency,

123 construct validity and sensitivity to change.

\section{METHODS}

127 The Pelvic Organ Prolapse Symptom Score

128 The POP-SS consists of seven items, each with a 5-point Likert response set

129 ( 0 =never, $1=$ occasionally, $2=$ sometimes, $3=$ most of the time, $4=$ all of the time) (Table

130 1). The question format and response set were modelled on those used by the ICIQ 
131 group to standardise outcome measures in pelvic floor dysfunction research and

132 clinical practice ${ }^{6}$. The items were developed from reviewing the literature in the

133 course of undertaking a number of prolapse-related Cochrane systematic 134 reviews $^{9,10,11}$, and from discussion with gynaecologists, physiotherapists and women 135 with prolapse. Some of the items are similar to those in other instruments since they 136 target universally acknowledged symptoms associated with prolapse (e.g. a feeling of 137 something coming down in the vagina). A total score (range 0 to 28 ) is calculated by

138 summing the seven individual symptom responses to derive the POP-SS score. In 139 addition, women indicate which one of the seven symptoms causes them most 140 bother (Table 1).

142 At an early stage the POP-SS was assessed in qualitative interviews with 10 women 143 (mean age 49 years) during which they completed the seven questions as part of a 144 larger questionnaire. Women, who had either stage I $(n=5)$ or II $(n=5)$ prolapse, were 145 purposively selected to represent the range of prolapse types (4 rectocele, 3 146 cystocele, 2 rectocele+cystocele, 1 uterine prolapse). The "think aloud" method ${ }^{12}$ 147 was used to encourage women to make explicit their understanding of the questions 148 and rationale for responses chosen. Women were also asked to comment on the 149 comprehensiveness and acceptability of the questionnaire. This approach provided 150 evidence of content validity and acceptability, since women could understand the 151 questions, and found them acceptable and relevant to the symptoms that troubled 152 them in relation to their prolapse ${ }^{13}$.

154 The POP-SS has to date been used in three studies ${ }^{14.15,16}$, undertaken by the same 155 research group, described below.

\section{Datasets}


160 In New Zealand in 2005, 435 women were followed up 12 years after giving birth, at 161 which time they had responded to a survey investigating postnatal urinary and faecal 162 incontinence ${ }^{17}$. All women completed the POP-SS, and a sub-group of 166 women 163 agreed to have objective prolapse assessment using the Pelvic Organ Prolapse -

164 Quantification system (POP-Q) ${ }^{18}$. Women were not known to be symptomatic of 165 prolapse: they were selected entirely on the basis of their involvement in the earlier 166 survey.

167

168 Study 2: Pelvic Organ Prolapse PhysiotherapY (POPPY) feasibility study ${ }^{15}$

169 In 2003/04, in a feasibility study at two Scottish centres, focussing on stage I or II 170 prolapse, 47 women were randomised to either a pelvic floor muscle training (PFMT) 171 intervention group or a control group receiving only a prolapse-related lifestyle advice 172 leaflet. Objective quantification of prolapse type and severity was carried out at 173 baseline and 6 months in both groups using the POP-Q ${ }^{18}$, and women completed a 174 postal questionnaire including the POP-SS at baseline, 20 and 26 weeks.

176 Study 3: Insertion of Mesh or sutures for PRolapsE Surgery Success (IMPRESS) ${ }^{16}$

177 In 2005 at one Scottish gynaecology centre, 66 women completed the POP-SS 178 before and 6 months after having prolapse surgery (anterior and/or posterior repair). 179 No POP-Q data were collected.

181 Analysis of the data resulting from these studies contributed information regarding 182 internal consistency, construct validity and sensitivity to change of the POP-SS.

\section{Psychometric properties}

185 It is desirable for questions within a scale which are measuring the same concept, in 186 this case extent of prolapse symptoms, to have high correlation; a property known as 
187 "internal consistency". Internal consistency of the POP-SS was assessed using data

188 from Studies 1, 2 and 3.

189

190 A valid scale is one which measures what it intends to, and this is best assessed by

191 comparison with a "gold standard" measure of the same quantity (criterion validity) ${ }^{19}$.

192 When no gold standard measure exists, as is the case for prolapse symptoms, it is

193 appropriate to assess construct validity instead. Hypotheses or constructs can be

194 established regarding the responses to the scale, and if the hypotheses are

195 supported by the data this provides evidence of construct validity. A form of

196 construct validity known as trait validity was investigated via the hypothesis that

197 scores at baseline (i.e. prior to any treatment) would be lowest in an asymptomatic

198 group of women (Study 1), followed by a conservative management group (Study 2),

199 and highest in a surgical intervention group (Study 3).

200

201 Ability to detect change in prolapse symptoms due to an intervention is an important 202 scale property. Sensitivity to change of the POP-SS was assessed by testing for a 203 significant pre- to post-intervention improvement in scores using data from Study 2 204 (PFMT intervention) and Study 3 (surgical intervention). The improvement in scores 205 was expected to be greater in Study 3.

\section{Statistical analysis}

208 The three data sets described above were analysed separately and combined as 209 appropriate to examine the properties of the POP-SS. The POP-SS scores were 210 found to be non-normally distributed in several of the samples, particularly post211 intervention when symptoms are likely to have resolved, thus primarily non212 parametric methods were used. 
214 Cronbach's alpha ${ }^{20}$ was used to assess internal consistency of the seven item POP-

215 SS using data from Studies 1,2 and 3. Good internal consistency was assumed if 216 Cronbach's alpha was between 0.7 and $0.9^{21}$. It is undesirable for alpha to be too 217 high as this suggests redundancy in the items of the scale.

219 In assessing trait validity, initially mean and median scores for the three study groups 220 were tabulated. Non-parametric one-way analysis of variance (Kruskal-Wallis) was 221 used to test for a significant difference between groups. Parametric analysis of 222 variance, with post-hoc t-tests of differences between group means with Bonferroni 223 correction, was also performed.

225 In terms of sensitivity to change, the Wilcoxon paired test was used to test for 226 statistically significant differences between pre- and post-intervention POP-SS scores 227 within studies. Differences between studies in pre- to post-intervention change in 228 score were tested using the Mann-Whitney $U$ test.

230 Analysis was undertaken using SPSS software and a 5\% level of significance was 231 used throughout.

\section{RESULTS}

Sample characteristics

236 The women in Study 3 (surgery group) were oldest and those in Study 1 237 (asymptomatic) were youngest, reflecting the differing study populations (Table 2).

239 Internal consistency

240 The correlation amongst questions within the POP-SS was assessed in individual 241 study datasets. Cronbach's alpha values (Table 3) indicate that the POP-SS seven 
242 items have good internal consistency, i.e. alpha > 0.7. The POPPY study (Study 2),

243 which had the smallest sample size, had slightly lower Cronbach's alpha for both 20

244 and 26 week follow up time-points.

Construct validity

247 The median POP-SS score at baseline was highest in the surgery study (Study 3),

248 followed by the conservative intervention study (Study 2), and lowest in the study of 249 asymptomatic women (Study 1) (Table 2). A significant difference between groups 250 (Kruskal-Wallis $\mathrm{X}^{2}=176.730, \mathrm{df}=2, \mathrm{p}<0.001$ ) was detected. The ProLong mean 251 score was significantly lower than that at baseline from POPPY (mean difference $2525.9,95 \% \mathrm{Cl}[-7.4,-4.4]$ ) and IMPRESS (mean difference $-10.9,95 \% \mathrm{Cl}[-12.2,-9.6]$ ), 253 and the baseline POPPY mean score was significantly lower than that for IMPRESS 254 (mean difference $-5.0,95 \% \mathrm{Cl}[-6.9,-3.1]$ ). That is, the POP-SS scores differed 255 between studies in a predictable way.

257 Table 1 highlights where differences in POP-SS scores between studies arose from. 258 In the asymptomatic group of women (Study 1) a low percentage responded 259 positively to having each of the seven symptoms. A feeling of incomplete bladder 260 (38\%) and bowel (46\%) emptying were the symptoms most commonly reported, and 261 the latter was the symptom which women said caused most bother. In contrast only $26216 \%$ reported a feeling of something coming down. Percentages were consistently 263 higher (in excess of $50 \%$ for each symptom) in the conservative treatment group 264 (Study 2), with the most commonly reported symptom being a feeling of something 265 coming down (79\%) (Table 1). In the surgical group (Study 3 ) the percentages were 266 highest of all studies, across all symptom questions. Most women in this study 267 reported a feeling of something coming down (89\%): this was both the most 268 prevalent symptom (but not reported by everyone) and the one which most women 269 identified as causing most bother. 
271 Sensitivity to change

272 In both the POPPY and IMPRESS studies a significant decrease in score after the 273 interventions was detected (Table 4). The average decrease in score was shown to 274 be significantly greater in the IMPRESS women than in the POPPY women $(z=-$ $2753.006, p=0.003$ ), i.e. there was greater improvement in the surgery group than the 276 PFMT group. Thus the POP-SS was able to detect the changes brought about by 277 both types of intervention, and a difference in the magnitude of the change was 278 distinguishable between studies.

280 DISCUSSION

281 Summary of aims

282 Our objective was to investigate the psychometric properties of a brief prolapse 283 symptom scale (POP-SS) which might be used as an outcome measure in future 284 trials of various prolapse interventions, and in clinical practice. No suitable validated 285 scale of this nature was available at the onset of our programme of work. There are 286 now a number of published prolapse instruments which are reported to be valid and 287 reliable, however their length and complexity may make them impractical for some 288 purposes. To our knowledge a reliable, valid and sensitive scale such as the POP289 SS is still lacking in the literature.

\section{Internal consistency}

292 Good internal consistency was confirmed across the three studies, and the POP-SS 293 compared favourably with other instruments in this respect. Digesu et al ${ }^{4}$ found 294 Cronbach's alpha to be in excess of 0.80 in their assessment of the P-QoL, and 295 Barber et al $^{2}$ reported Cronbach's alpha of 0.82 for the Pelvic Organ Prolapse 296 Distress Inventory and 0.97 for the Pelvic Organ Prolapse Impact Questionnaire, 297 which are the relevant subcales of the PFDI and PFIQ. It is reassuring that all POP- 
298 SS items appear to be measuring the same trait, that is, there is homogeneity of the

299 items within the scale. The value of Cronbach's alpha did not exceed 0.9 which 300 would have suggested that the questions were too highly correlated and that some 301 items were redundant. The findings suggest that a simple summation of scores over 302 the seven symptom questions makes a reasonable index ${ }^{19}$.

304 It is interesting that the internal consistency of the POP-SS is good (Cronbach's 305 alpha 0.823 ) in a sample of women selected without knowledge of their status with 306 regards to prolapse (ProLong). This is encouraging if the POP-SS were to be used 307 in trials of interventions to prevent prolapse.

\section{Validity}

310 The three study populations were representative of women with differing profiles of

311 prolapse. Study 1 comprised a group of women who had participated in a post-natal 312 survey 12 years previously, and for whom prolapse status was therefore unknown. 313 Study 2 included women opting for conservative treatment, predominantly with stage 314 I or II prolapse. Finally, Study 3 included women with prolapse of stage II or greater, 315 having prolapse repair surgery. These groups of women would be expected to have 316 different symptoms leading to their differing treatment choices, or in the case of 317 Study 1, to no treatment for prolapse being sought. The ability of the POP-SS to 318 differentiate between these groups, as indicated by the significant difference in 319 scores, supports the trait validity of the scale. The predicted ordering in average 320 group scores was observed in the data, providing additional evidence of validity. In a 321 similar analysis the P-QoL domain scores were also found to differ significantly 322 between symptomatic and asymptomatic women ${ }^{4}$. Other studies have investigated 323 validity in terms of the relationship between symptom scores and prolapse severity, 324 however, to date, it is not clear whether increasing symptoms are correlated with 
325 increasing prolapse severity ${ }^{22}$. Analysis of the relationship between the POP-SS

326 and the POP-Q is underway, and will contribute information to this debate.

Sensitivity to change

330 POP-SS could detect change due to both conservative and surgical interventions,

331 and as expected the improvement in symptoms was greater in women who had

332 surgery. This is an important property for a scale which is to be used in trials

333 establishing the effectiveness of interventions for treatment of prolapse. The

334 sensitivity to change of the P-QoL and PFDI/PFIQ has not been reported. The short

335 forms of the PFDI and PFIQ were however found to have moderate to excellent

336 responsiveness 3 to 6 months after surgery ${ }^{3}$.

338 Implications for further research/use of POP-SS

339 Our aim was to develop a scale which was brief and contained only the key 340 symptoms important in obtaining a view of how prolapse is affecting a woman. It 341 could be argued that the three questions within the POP-SS relating to bladder and 342 bowel are not symptoms experienced exclusively by women with prolapse. 343 Generally we avoided in our scale such questions, however these symptoms, more 344 than others, are linked frequently with prolapse and were regarded to be worth 345 including. The feeling of incomplete emptying of the bladder and bowel were the 346 symptoms most commonly reported in the ProLong study (Study 1) in which women 347 did not necessarily have prolapse. This perhaps reflects the fact that these 348 symptoms are experienced generally by women other than those with prolapse. The 349 prevalence of these symptoms was, however, far higher in the studies of women with 350 confirmed prolapse. 
352 The POP-SS was developed from a wide perspective, drawing on published

353 research, clinical expertise and qualitative data from women with prolapse. It would 354 be desirable to undertake further qualitative work investigating how women with 355 different profiles respond to POP-SS items, and how well changes in scores reflect 356 important modifications in their symptoms. Data are being gathered currently on the 357 test-retest reliability of the POP-SS, and on its relationship with the observed POP-Q 358 measure. Examination of the psychometric properties of the POP-SS in other 359 treatment groups, for example women being fitted with a vaginal pessary, is also 360 warranted.

362 In prolapse research the choice of an appropriate measure is still the subject of 363 debate. There is a need to review and produce recommendations on the currently 364 available prolapse questionnaires.

\section{Conclusion}

367 It has been shown that the POP-SS is a measure with good internal consistency; it is 368 valid as a measure of prolapse symptoms as scores differed predictably between 369 groups of women known to differ in their prolapse symptoms; finally, it is sensitive to 370 the change brought about by treatment for prolapse, specifically surgical repair and 371 PFMT.

373 The POP-SS is a brief questionnaire which is acceptable to women and lends itself to 374 both the research and the clinical environment.

376 Acknowledgements

377 Collaborators in each of the studies: Dr lan Ramsay, Dr Stewart Pringle, Dr Robert

378 Hawthorn, Dr John Tierney, Dr Christine Bain, Dr Kevin Cooper, Ms Lynne Swan, 
379 Professor Don Wilson, Professor Peter Herbison, Dr Nicola Dean, Ms Gaye Ellis, Dr

380 Sabeena Allahdin.

382 The Chief Scientist Office, Scottish Government, funds Suzanne Hagen's post.

\section{Disclosure of interests}

385 None.

\section{Contribution to authorship}

$388 \mathrm{SH}$ was principal investigator on one study, carried out the main data analysis and 389 drafted the manuscript. CG was principal investigator on one study, assisted with 390 interpretation of the findings, commented on draft manuscripts and approved the final 391 submission. LS was involved in the analysis of the POP-SS data, commented on 392 draft manuscripts and approved the final submission. DS was co-investigator on one 393 study, was involved in data collection, commented on draft manuscripts and 394 approved the final submission. CB carried out the qualitative research on the POP395 SS, drafted material for the manuscript and approved the final submission.

\section{Details of ethical approval}

398 For each study the procedures received ethical approval from the relevant research

399 ethics committee.

400

401 1. ProLong: Lower South Regional Ethics Committee, New Zealand; Ethics ref.

402 LRS/05/04/009; approved 31 May 2005,

403 2. POPPY: a) Southern General Hospital Ethics Committee; Paper no. EC/02/S/115;

404 approved 25 September 2002; b) Grampian Research Ethics Committee; Project no.

405 02/0243; approved 11 March 2003 
406 3. IMPRESS: Grampian Research Ethics Committee; Project no. 04/MRE10/72;

407 approved 9 May 2005

408

409 Funding

410 1. ProLong: University of Otago Postgraduate Scholarship in Obstetrics and

411 Gynaecology

412 2. POPPY: Health Services Research Committee grant, Chief Scientist Office,

413 Scottish Government

414 3. IMPRESS: None

415

416

417 Table/ Figure Caption List

418

419 Table 1 Pelvic Organ Prolapse Symptom Scale: percent of women responding

420 positively to symptom questions in each study

421

422 Table 2 Characteristics of women from included studies

424 Table 3 Internal consistency of the POP-SS

425

426 Table 4 Sensitivity to change of the POP-SS: paired tests 
427 Table 1 Pelvic Organ Prolapse Symptom Scale: percent of women responding 428 positively to symptom questions in each study

430 How often during the last four weeks have you had the following symptoms ( $0=$ never, 431 1=occasionally, 2=sometimes, 3=most of the time, 4=all of the time):

\begin{tabular}{|l|l|r|r|r|}
\hline & & $\begin{array}{r}\text { Study 1 } \\
\text { ProLong } \\
\mathrm{N}=435\end{array}$ & $\begin{array}{r}\text { Study 2 } \\
\text { POPPY } \\
\mathrm{N}=47\end{array}$ & $\begin{array}{r}\text { Study 3 } \\
\text { IMPRES } \\
\mathrm{N}=66\end{array}$ \\
\hline A1 & $\begin{array}{l}\text { a feeling of something coming down } \\
\text { from or in your vagina? }\end{array}$ & $16.2 \%$ & $78.7 \%$ & $89.2 \%$ \\
\hline A2 & $\begin{array}{l}\text { an uncomfortable feeling or pain in your } \\
\text { vagina which is worse when standing? }\end{array}$ & $13.0 \%$ & $67.4 \%$ & $70.8 \%$ \\
\hline A3 & $\begin{array}{l}\text { a heaviness or dragging feeling in your } \\
\text { lower abdomen / tummy? }\end{array}$ & $27.0 \%$ & $63.8 \%$ & $81.5 \%$ \\
\hline A4 & $\begin{array}{l}\text { a heaviness or dragging feeling in your } \\
\text { lower back? }\end{array}$ & $23.7 \%$ & $59.6 \%$ & $66.2 \%$ \\
\hline A5 & $\begin{array}{l}\text { a need to strain (push) to empty your } \\
\text { bladder? }\end{array}$ & $24.1 \%$ & $56.5 \%$ & $72.3 \%$ \\
\hline A6 & $\begin{array}{l}\text { a feeling that your bladder has not } \\
\text { emptied completely? }\end{array}$ & $38.1 \%$ & $63.8 \%$ & $87.7 \%$ \\
\hline A7 & $\begin{array}{l}\text { a feeling that your bowel has not } \\
\text { emptied completely? }\end{array}$ & $46.4 \%$ & $63.8 \%$ & $76.9 \%$ \\
\hline *A8 & $\begin{array}{l}\text { which of the symptoms above } \\
\text { (questions A1 to A7) causes you most } \\
\text { bother? }\end{array}$ & $39.3 \%$ & $\mathrm{~A} / \mathrm{A}$ & $40.0 \%$ \\
\hline
\end{tabular}

433 * The symptom most often identified as causing most bother is shown, with the 434 percentage of respondents which chose this symptom. This question was used only 435 in Study 1 and Study 3. 
436 Table 2 Characteristics of women from included studies

\begin{tabular}{|c|c|c|c|}
\hline Variable & Study 1 & Study 2 & Study 3 \\
\hline Maximum sample size & $\begin{array}{r}435 \\
(166 \text { with } \\
\text { POP-Q) }\end{array}$ & 47 & 66 \\
\hline $\begin{array}{l}\text { Median age in years } \\
\text { (range) }\end{array}$ & $\begin{array}{r}40 \\
(28,57)\end{array}$ & $\begin{array}{r}57 \\
(31,72)\end{array}$ & $\begin{array}{r}61 \\
(43,84)\end{array}$ \\
\hline $\begin{array}{r}\text { POP-Q at baseline } \mathrm{n}(\%) \text { : } \\
\text { Stage } 0 \\
\text { II } \\
\text { III }\end{array}$ & $\begin{array}{r}3(2) \\
59(35) \\
101(61) \\
3(2)\end{array}$ & $\begin{array}{r}{ }^{\#} 1(2) \\
13(29) \\
30(67) \\
{ }^{\#} 1(2)\end{array}$ & $\begin{array}{r}\text { all women were } \\
\text { stage II, III } \\
\text { or IV }\end{array}$ \\
\hline $\begin{array}{l}\text { Leading edge POP } \\
\text { type } \mathrm{n}(\%): \quad \text { anterior } \\
\text { posterior } \\
\text { anterior= } \\
\begin{aligned} \text { posterior } \\
\text { superior }\end{aligned}\end{array}$ & $\begin{array}{r}86(52) \\
32(19) \\
43(26) \\
3(1)\end{array}$ & $\begin{array}{r}17(70) \\
4(16) \\
2(8) \\
1(4)\end{array}$ & $\begin{array}{l}30(48) \\
13(20) \\
{ }^{*} 19(30)\end{array}$ \\
\hline $\begin{array}{r}\text { Median POP-SS (range) } \\
\text { Baseline }\end{array}$ & $1(0,16)$ & $8(0,21)$ & $13(3,28)$ \\
\hline $\begin{array}{r}20 \text { wks/6 mnths post-intv } \\
26 \text { weeks post-intv }\end{array}$ & $\begin{array}{l}n / a \\
n / a\end{array}$ & $\begin{array}{r}7.5(2,21) \\
6(1,21)\end{array}$ & $\begin{array}{r}3(0,22) \\
n / a\end{array}$ \\
\hline
\end{tabular}

437 women who had both anterior and posterior repair were assumed to have equal 438 leading edges

439 \# 1 woman presenting with prolapse symptoms but found to be stage 0 on 440 examination was included. 1 woman with stage 3 prolapse was erroneously 441 included. 
442 Table 3 Internal consistency of the POP-SS

\begin{tabular}{|l|r|r|}
\hline Study & Cronbach's alpha & $\mathrm{N}$ \\
\hline Study 1 & 0.823 & 421 \\
\hline Study 2: & 0.798 & 45 \\
Baseline & 0.737 & 38 \\
20 weeks & 0.723 & 39 \\
26 weeks & & \\
\hline Study 3: & 0.819 & 65 \\
Pre-op & 0.828 & 62 \\
6-mnths post-op & & \\
\hline
\end{tabular}

443 
444 Table 4 Sensitivity to change of the POP-SS: paired tests

\begin{tabular}{|l|r|r|r|r|r|r|}
\hline Study & $\begin{array}{r}\text { mean pre- } \\
\text { intervention }\end{array}$ & $\begin{array}{r}\text { mean post- } \\
\text { intervention }\end{array}$ & $\begin{array}{r}\text { mean difference } \\
\text { (pre-post) }\end{array}$ & Wilcoxon & $\begin{array}{r}\mathrm{p} \\
\text { value }\end{array}$ \\
\hline Study 2 & 9.05 & 6.11 & 3.47 & ${ }^{*} 17$ & -2.308 & 0.021 \\
\hline Study 3 & 13.52 & 4.34 & 9.20 & 61 & -6.069 & $<0.001$ \\
\hline
\end{tabular}

* only data from intervention women are included: control women received only a

446 lifestyle leaflet, and no significant change in POP-SS score was detected

447

448

449 
1 Abrams P, Cardozo L, Khoury S, Wein A editors. Incontinence: 3rd International Consultation on Incontinence. Third ed. Paris: Health Publications Ltd.; 2005.

2 Barber MD, Kuchibhatla MN, Pieper CF, Bump RC. Psychometric evaluation of 2 comprehensive condition-specific quality of life instruments for women with pelvic floor disorders. Am.J.Obstet.Gynecol. 2001 Dec;185(6):1388-1395.

3 Barber MD, Walters MD, Bump RC. Short forms of two condition-specific quality-of-life questionnaires for women with pelvic floor disorders (PFDI-20 and PFIQ-7). Am.J.Obstet.Gynecol. 2005 Jul;193(1):103-113.

4 Digesu GA, Khullar V, Cardozo L, Robinson D, Salvatore S. P-QOL: a validated questionnaire to assess the symptoms and quality of life of women with urogenital prolapse. Int.Urogynecol.J.Pelvic Floor Dysfunct. 2005 May-Jun;16(3):176-81.

5 Price N, Jackson SR, Avery K, Brookes ST, Abrams P. Development and psychometric evaluation of the ICIQ Vaginal Symptoms Questionnaire: the ICIQ-VS. BJOG 2006 Jun;113(6):700-712.

6 Abrams P, Avery K, Gardener N, Donovan J. The International Consultation on Incontinence Modular Questionnaire: www.iciq.net. The Journal of Urology, 2006 3;175(3):1063-1066.

7 Avery K, Donovan J, Peters TJ, Shaw C, Gotoh M, Abrams P. ICIQ: A brief and robust measure for evaluating the symptoms and impact of urinary incontinence. Neurourol.Urodyn. 2004;23(4):322-330.

8 Rogers RG, Coates KW, Kammerer-Doak D, Khalsa S, Qualls C. A short form of the Pelvic Organ Prolapse/Urinary Incontinence Sexual Questionnaire (PISQ-12). Int.Urogynecol.J.Pelvic Floor Dysfunct. 2003 Aug;14(3):164-8.

9 Adams E, Thomson A, Maher C, Hagen S. Mechanical devices for pelvic organ prolapse in women. Cochrane Database of Systematic Reviews 2004, Issue 2. Art. No.: CD004010. DOI: 10.1002/14651858.CD004010.pub2.

Hagen S, Stark D, Maher C, Adams E. Conservative management of pelvic organ prolapse in women. Cochrane Database of Systematic Reviews 2004, Issue 2. Art. No.: CD003882. DOI: 10.1002/14651858.CD003882.pub3.

11 Maher C, Baessler K, Glazener CMA, Adams EJ, Hagen S. Surgical management of pelvic organ prolapse in women. Cochrane Database of Systematic Reviews 2004, Issue 4. Art. No.: CD004014. DOI: 10.1002/14651858.CD004014.pub3.

12 Gilhooly K, Green C. Protocol analysis: theoretical background. In: Richardson JTE, editor. Handbook of Qualitative Research Methods for Psychology and the Social Sciences. First ed.: The British Psychological Society; 1996. p. 43-54.

13 Bugge C, Hagen S, Glazener C. The POPPY study: A qualitative evaluation of a pelvic organ prolapse outcome questionnaire. ICS UK 12th Annual 
Scientific Meeting; March 2005; Glasgow, UK.

14 Dean N, Martin L, Herbison P, Wilson D, Glazener C, MacArthur C, Hagen S, Grant A, Toozs-Hobson P, Bain C. Assessment of Pelvic Floor Dysfunction in Nulliparous Women: A Comparative Study. International Continence Society, 36th Annual Meeting; 27 Nov - 1 Dec 2006; Christchurch, New Zealand.

15 Hagen S, Stark D, Sinclair L, Glazener C, Ramsay I. A feasibility study for a randomised controlled trial of a pelvic floor muscle training intervention for women with pelvic organ prolapse. International Continence Society, 36th Annual Meeting; 27 Nov - 1 Dec 2006; Christchurch, New Zealand.

16 Allahdin S, Glazener CMA, Bain C. Feasibility study for a randomised controlled trial evaluating the use of absorbable mesh, polydioxanone and polyglactin sutures for anterior and posterior vaginal wall prolapse repairs. International Continence Society, 36th Annual Meeting; 27 Nov - 1 Dec 2006; Christchurch, New Zealand.

17 Glazener C, Herbison G, MacArthur C, Lancashire R, McGee M, Grant A, et al. New postnatal urinary incontinence: obstetric and other risk factors in primiparae. BJOG: An International Journal of Obstetrics and Gynaecology 2006 02/32;113(2):208-217.

18 Bump RC, Mattiasson A, Bo K, Brubaker LP, DeLancey JO, Klarskov P, et al. The standardization of terminology of female pelvic organ prolapse and pelvic floor dysfunction. Am.J.Obstet.Gynecol. 1996 Jul;175(1):10-17.

19 Streiner DL, Norman GR. Health measurement scales, a practical guide to their development and use. Second ed. Oxford: Oxford University Press; 1995.

20 Cronbach LJ. Coefficient Alpha and the internal structure of a tests. Psychometrika 1951;16:297-297-334.

21 Nunnally JC. Psychometric Theory. Second ed. New York: McGraw-Hill; 1978.

22 Tan JS, Lukacz ES, Menefee SA, Powell CR, Nager CW. Predictive value of prolapse symptoms: a large database study. International Urogynecology Journal 2005 06/01;16(3):203-209. 
455

456 